\title{
Derrida, Teaching and the Context of Failure
}

\author{
Ian Munday
}

\begin{abstract}
The aim of this paper is to bring critical attention to the ways in which notions of 'success' and 'failure' are applied to teaching and learning in schools in England and Wales. The main philosophical text that guides the discussion is Derrida's 'Signature event context', which contains a reading of J.L. Austin's theory of the performative utterance. Derrida finds much to admire in Austin's philosophising. However, he argues that Austin's treatment of context misses something important about how things are done with words. Derrida maintains that, having shown how truth claims are bound up with performative concerns, Austin takes a step backwards by fixating on external contextual factors that must be in place for the performative utterance to be happy-for it to 'succeed' in doing what the speaker intends it to do. This ignores the iterability of language and the ways in which words are ultimately bound neither by the intentions of the speaker, nor by any other aspect of the environment in which the utterance takes place. The current thinking in regards to successful teaching and learning invites a comparison with Austin's treatment of context - for a lesson to be successful, a set of contextual factors must be put in place. In this paper, I argue that treating teaching and learning in these terms represents an overdetermined understanding of 'success' and 'failure' that sees language as something to be tamed by context. Once we recognise that words cannot always or necessarily be brought under control then this will open the door to creative ways of thinking about teaching and language.
\end{abstract}

\section{Introduction}

In the current British educational climate, teachers are expected to know what giving a good lesson involves. They should also know what one has to 'do' (or not 'do') if one is to give an 'outstanding', 'satisfactory' or 'unsatisfactory' lesson. In short, if teachers are unfamiliar with the criteria for success and failure, then the latter is the most likely outcome. There is a strange artificiality that seems to accompany the categories 'unsatisfactory', 'satisfactory', 'good' and 'outstanding' - during my time as a teacher in a comprehensive school, I vividly recall a talk in which the speaker informed us that 'satisfactory' no longer meant satisfactory. What this story reveals is a certain kind of scepticism in the face of language - that 'satisfactory' no longer means satisfactory reveals a deep suspicion of how words ordinarily do what they do. In this paper, I want to bring attention to linguistic issues pertaining to the role played by contextual factors when establishing whether or not teaching fails or succeeds. Such contextual factors are often alluded to or brought in to counter the perceived dangers of language. Teachers should not talk too much and what they say should be utterly transparent. In the meantime, they should make sure that they supply seating plans etc. to gain maximum control of the classroom so that learning takes place. The philosophical material that guides this discussion derives from Jacques Derrida's reading of Austin's theory of the performative utterance (found in Derrida's famous essay 'Signature event context'). As we shall see, Derrida's reading of Austin is by no means wholly critical. The former finds much that is 
interesting and important in Austin's philosophical project. Indeed, Derrida applauds Austin's ability to show how the language of truth is bound up with the language of performance. However, he argues that Austin's overdetermined treatment of context misses something important about the functioning of language. In the last part of the paper, I will attempt to show how Derrida's discussion of context and what is meant by a linguistic 'event' creates a space for questioning deeply held assumptions about 'successful' teaching and learning and the understanding of 'failure' that accompanies such assumptions. Before delving into the complexities of Derrida's argument it may be helpful to provide an outline of Austin's work on performatives.

\section{The performative utterance}

In How to do things with words, Austin attempts to distinguish performative utterances which 'do' things from constative utterances that state things. He notes that performative utterances cannot be thought of purely in terms of truth and falsity. Such utterances include 'I christen this ship the ...' and 'I now declare you man and wife'. Austin points out that to utter such sentences is:

...not to describe my doing of what I should be said in so uttering to be doing or to state that I am doing it: it is to do it. None of the utterances cited is either true or false: I assert this as obvious and do not argue it. It needs argument no more than 'damn' is not true or false: it may be that the utterance 'serves to inform you' - but that is quite different ... When I say, before the registrar or altar, etc., 'I do', I am not reporting on a marriage: I am indulging in it. (Austin, 1976, p. 6)

By focusing on the kind of utterance that 'does' something, Austin brings attention to an area of language that had been previously ignored by philosophers of a descriptivist persuasion (performative utterances do not describe anything). Implied in the notion of the description or statement is the implication of a distance between language and world, between words and actions. When we look at an utterance such as 'I christen this ship the ...' no such division is apparent - to speak is to act, to indulge. Having recognised this aspect of language, Austin introduces the distinction between performative and constative utterances. Constative utterances state things and can be considered in terms of truth and falsity, whilst the utterance of a performative is to 'do' something with words. After making this distinction, Austin focuses on performative utterances and is obliged to consider the 'constraints or conditions that they operate under which ensure that they communicate or do their work as perfectly as they do, as perfectly as the most unobjectionable true-or-false statements do theirs' (Cavell, 2005, p. 158). Austin argues that the success of performative utterances (though not divorced from questions of truth or falsity) is subject to conditions of infelicity or unhappiness. Infelicity/unhappiness occurs when the performative utterance fails to achieve its intended effect. Such failure results from some lack or inadequacy within the total speech situation. An example might be a wedding in which the person presiding over the ceremony does not have the legal authority to marry the participants. This contextual factor means that the speaker's words do not have their intended effect, and the performative utterance is therefore unhappy. Austin calls such constraints 'felicity conditions' and identifies six of them. 
Having recognised the distinction between constative utterances (subject to conditions of truth and falsity) and performative utterances (subject to conditions of happiness or unhappiness) Austin comes to see that it begins to break down. Although constative utterances represent truth claims, constatives are subject to conditions of infelicity; if the cat is under the mat, then the statement 'the cat is on the mat' (Austin, 1976, p. 9) is clearly unhappy. More than this, truth claims are integral to performative utterances:

'I warn you that the bull is about to charge' is the fact, if it is one, that the bull is about to charge: if the bull is not, then indeed the utterance 'I warn you that the bull is about to charge' is open to criticism-but not in any of the ways we have hitherto characterized as varieties of unhappiness. We should not in any case say that the warning was void-i.e. that he did not warn but only went through a form of warning - nor that it was insincere: we should feel much more inclined to say that the warning was false or (better) mistaken, as with a statement. So that considerations of the happiness and unhappiness type may infect statements (or some statements) and considerations of the type of truth and falsity may infect statements (or some statements) and considerations of the type of truth and falsity may infect performatives (or some performatives). (p. 6)

Ultimately Austin comes to argue that to think of truth claims operating within some purified zone of stating is a fundamentally flawed vision of language. Rather, claims of essential or abstract truth are positioned by contextual factors that take over the whole speech situation. Austin is not saying that we cannot speak of truth. However, he demonstrates that conditions applicable to the language of doing apply to the language of stating; that in a complex way, constative statements are necessarily performative and performatives are bound up with truth claims.

Having failed to make a clear distinction between the constative and performative through reference to grammar and semantics, Austin decides to analyse the performative utterance in greater detail. He looks at the different aspects of the performative; the locutionary aspect, which concerns the form of the words, the illocutionary force of performatives (speech acts which perform an action through their very utterance) and the perlocutionary effects of performatives (what is done by the performative utterance). Austin says very little about the locutionary or perlocutionary aspects of the performative. Instead, he looks more closely at the illocutionary force enacted by words and their capacity to 'do things'.

\section{Austin, Derrida and context}

Derrida's interest in Austin's project derives in part from the latter's recognition that in identifying the ways in which words can do things the focus moves away from thinking of language in terms of signification where words stand as markers for ideas, for some truth external to language, to an emphasis on 'communicating a force through the impetus [impulsion] of a mark' (Derrida, 1988, p. 13). We should note here that for Derrida, the notion of the mark acts as a replacement for the sign. The sign, with its binary distinction between signifier and signified remains trapped within the metaphysics of presence. It assumes some origin of meaning and a fullness that precedes the signifier. Derrida's 'mark' is the written word stripped of signification (emptied out of meaning) that indicates a presence in the form of a trace. The mark indicates presence, yet in Derrida's terms it exists as the 
absent origin - the mark stripped of meaning. Meaning/concept is an effect produced through the force [impetus] of the mark. To understand things in this way is to understand all meaning as textual - there is no outside text. When Austin shows how issuing a performative utterance is not to report on language but to indulge in it, he appears to recognise the impossibility of adopting a stance that it external to language. This is why Derrida notes that:

As opposed to the classical assertion, to the constative utterance, the performative does not have its referent (but here the word is certainly no longer appropriate, and this precisely is the interest of the discovery) outside of itself or, in any event, before and in front of itself. It does not describe something that exists outside language and prior to it. (p. 13)

Derrida argues that Austin has shattered the concept of communication as a purely semiotic, linguistic or symbolic concept. Communication is no longer considered in terms of 'transference of semantic content' or fixed in its orientation towards truth. Derrida praises Austin's patience and openness, the fact that the work is in constant transformation, that it acknowledges its impasses. Nevertheless, despite the fact that for Austin meaning no longer has a 'referent in the form of a thing or of a prior or exterior state of things', Derrida argues that Austin undoes all his good work by missing something important about the structure of locution which effects the ternary distinction between locutions, illocutions and perlocutions.

What does this amount to? It seems to have everything to do with the importance to Austin's project of an exhaustively determined context. One of the essential elements to this 'remains, classically, consciousness, the conscious presence of the speaking subject in the totality of his speech act'. Performative communication is bound up with intentional meaning:

The conscious presence of speakers or receivers participating in the accomplishment of a performative, their conscious and intentional presence in the totality of the operation implies teleologically that no residue [reste] escapes the present totalisation. (p. 14)

I take this to mean that Austin, having shown how the outside to language invoked by the 'referent in the form of a thing or a prior exterior state of things' (p. 14) breaks down in the colonisation of the constative by performative concerns, then goes on to reinstate external presence in the figure of the speaking subject. The success of an utterance depends on whether or not my words do what I intend them to do: 'therefore we find an exhaustibly definable context, of a free consciousness present to the totality of the operation, and of absolutely meaningful speech master of itself: the teleological jurisdiction of an entire field whose organising center remains intention' (p. 14). If my intentions succeed they must do so with due correctness and completeness. This can only be accomplished if other factors (felicity conditions external to the utterance) are in place. If the priest is not qualified to marry me, then I will not be married. Derrida notes that Austin's procedure is:

...rather remarkable and typical of that philosophical tradition with which he would like to have so few ties. It consists in recognizing that the possibility of the negative (in this case, of infelicities) is in fact a structural possibility, that failure is an essential risk of the operations under consideration; then in a move which is almost immediately simultaneous, in the name of a kind of ideal regulation, it excludes that risk as accidental, exterior, one which teaches us nothing about the linguistic phenomenon being considered ... Thus, for example, concerning the conventionality 
without which there is no performative, Austin acknowledges that all conventional acts are exposed to failure: 'it seems clear in the first place that, although it has excited us (or failed to excite us) in connexion with certain acts which are or are in part acts of uttering words, infelicity is an ill to which all acts are heir which have the general character of ritual or ceremonial, all conventional acts: not indeed that every ritual is liable to every form of infelicity (but then nor is every performative utterance)' (Austin's emphasis). (p. 15)

Derrida notes, and applauds, Austin's interest in the 'negative', in communicative failure. In this respect, Austin's project seems in line with non-analytical strands of philosophy. However, Austin then seems to take a step backwards by focusing solely on the contextual surroundings 'the conventionality constituting the circumstance of the utterance' (p. 15). Derrida's point is that Austin misses the conventionality intrinsic to what constitutes the speech act (locution itself). He notes that: 'Ritual is not a possible occurrence, but rather, as iterability, a structural characteristic of every mark' (p. 15). What does this amount to? It seems that words if they are to mean anything at all, must be repeatable and repeated as ritual. Derrida's point is that language is itself performative and exercises force in its own right. Austin's mistake is to move away from the 'wordness' (the 'graphematic' aspects) of language to concentrate on forces that enact themselves on language and are thought to be somehow exterior to it. For Derrida, words are subject to an internal force and movement. It is not the case (as Austin might have it) that the context determines the force of words. Rather, an unlimited number of possible contexts are internal to the words themselves. The word or concept is never at one with itself. Derrida insists that he is not referring to the polysemy of language but its iterability. If we perceive the forces in language to be external, then the context determines meaning. Of course, the organising centre of context in Austin is the individual speaking subject. To show how this particular contextual feature comes under duress, it will be helpful to consider what Derrida has to say about signatures.

\section{Signatures}

Derrida notes that it is the critique of linguisticism that most interests him about Austin - that 'no single, simple criterion of grammar and 'vocabulary' can distinguish constatives from performatives (Derrida, 1988, p. 19). However, Derrida notes that Austin explains his preference for the present-indicative-active voice- 'I promise', 'I christen this ...', 'I ...' -in non-linguistic terms. Despite not being in favour of linguisticism, a move away from language is not what (in Derrida's eyes) is called for. Derrida's suspicion relates to what Austin calls the 'source' (the translator notes that Austin's term is 'utterance-origin') of the linguistic utterance, the ' $\mathrm{I}$ ' that does something with words. Derrida notes that Austin both has no doubt that 'the source of an oral utterance in the present indicative active is present to the utterance' (p. 19) and that this is equally true in written (in its conventional sense) examples:

When there is not, in the verbal formula of the utterance, a reference to the person doing the uttering, and so the acting, by means of the pronoun 'I' (or by his personal name), then in fact he will be 'referred to' in one of two ways:

a. In verbal utterances, by his being the person who does the uttering-what we may call the utterance-origin which is 
used generally in any system of verbal reference-coordinates.

b. In written utterances (or 'inscriptions'), by his appending his signature (this has to be done because, of course, written utterances are not tethered to their origin in the way spoken ones are). (Austin cited in Derrida, 1988, pp. 19-20)

So, the source of the utterance is the speaking subject in cases of speech, and in written form appears as the signature. My presence as speaking subject is manifested in written form in the guise of my signature. Let us begin by looking at the written example and consider issues of 'source' or 'origin' as they pertain to it. Problems immediately arise when we consider the question: when do I write my signature for the first time? Commonsense might indicate that this occurs when I first scribble down that mark that is to become my signature. However, to suggest it will 'become' my signature suggests that it is not my signature yet. If this is true, then the first occasion of my signature might be the first time I write it on a cheque or a form. Unfortunately, this is also inaccurate, because, for it to be my signature it has to be repeated. Are we then bound to the strange conclusion that the second time I put the mark of my signature on a form or cheque is the first time I have used my signature? No, because the whole point of my signature being my signature is that it must be repeated endlessly as ritual.

It will be helpful to consider how issues pertaining to context fit in here. Every time I write my signature, I do so in a different context - my signature is in some way different each time it makes an appearance. The 'significance' attached to signing a marriage license or signing a cheque is quite different. By the same token, my signature carries with it its old contexts and is in a sense full of the contexts in which it will enter. In a radical sense, it is not at one with itself, nor is it under my direct control, even though it functions as my representative in my absence. More than this its previous, present and future contexts are internal to it.

If we see the signature as in some way 'out of joint', might this simply represent the lack of fullness/presence that is traditionally ascribed to writing in contrast to speech? After all, Austin notes that written utterances are not tethered to their origin in the ways spoken ones are. For Derrida, to see things in this way is to miss the wordness of our understanding of things. What is applicable to signatures is applicable to all words. Just as the 'mark' on the page represents the absent trace of my signature, the same thing is true of all words. Consequently, what applies to the signature applies to language in general regardless of whether it is 'written' (in the traditional sense of the word) or not. Just as the signature appears to indicate full presence to my words, this illusory quality vis-à-vis presence also applies to the speaking subject. This control of context and therefore meaning is central to the tradition that has given speech a particular dominance in the linguistic hierarchy over writing. Derrida, in showing that words carry their contexts with them, means that the fullness and completeness, the presence ascribed to the speech situation is never fully realised; never mind the force of the present context, the words will not allow it.

Through his adherence to the law of iterability Derrida is, in a sense, putting forward a general theory - all words and utterances are subject to iterability-the ways in which this manifests itself will vary, but all words are essentially iterable. Derrida seems to sense that Austin anticipates problems concerning a general unhappiness that applies to language but turns away from it: at one point Austin wonders if there is not 'some very general high-level doctrine' that might 'embrace both what we have called infelicities and these other "unhappy" features of the doing of actions - in our case actions containing a performative utterance - in a single doctrine' (Austin cited in Derrida, 1988, p. 16). However, he maintains 
that he is not concerned with this kind of unhappiness and notes that: 'Features of this sort would normally come under the heading of "extenuating circumstances" or of "factors reducing or abrogating the agent's responsibility" (p. 16). Derrida argues that Austin is referring here to quotation - every performative utterance-indeed every utterance can be quoted. But for Austin, this possibility is both 'abnormal' and 'parasitic' (p. 16) - it should not be regarded as a feature of the 'ordinary' or of ordinary language. Here we might note that Austin's identification of the 'ordinary' is resistant to the notion of words being somehow taken out into the ether, untethered from their original source. Yet, as we have already seen (Derrida has shown us), words are never under our direct control in the first place. More than this, the repetition of words and the fact that they can be and are subject to quotation are factors that are internal to language and the very condition for anything to mean anything. In turning away from this 'general doctrine' Austin looks inward to the singularity of the individual utterance and the specificity of the total speech act situation. Derrida captures the problems pertaining to this inward turn when he discusses the linguistic event.

\section{Events}

It is necessary at this point to recognise what might seem like an obvious objection to Derrida's development of locutions. It would appear that people have got married and boats have been christened. Indeed, if people fail to get married despite the issuing of the utterance 'I now declare you man and wife' then this may be to do with the kinds of unhappiness that Austin identifies. Derrida maintains that this is 'perhaps' (Derrida, 1988, p. 17) the case, but surely there is something grudging, absurd or deliberately obtuse about saying 'perhaps'one might imagine that Derrida's wife would not be too pleased. Of course, Derrida cannot, in a straightforward sense, be suggesting that such things do not occur. Rather, it is the "pure singularity of the event' that is in doubt. To think that there can be a 'pure singularity of the event' is to be caught in the grip of a false metaphysics and a false security vis-àvis language. It is this false security that Derrida wishes to expose and move beyond. There is of course a genuine security that we ordinarily have in our lives-people do get married. Moreover, the fact that statements like 'I now declare you man and wife' or 'I christen this ship the ...' make any sense and represent instances of doing things with words is because they are iterable in structure:

I take things up here from the perspective of positive possibility and not simply as instances of failure or infelicity: would a performative utterance be possible if a citational doubling [doublure] did not come to split and dissociate from itself the pure singularity of the event? (p. 17)

The formulations 'I now pronounce ...' etc. could only succeed if they repeated a coded or iterable utterance. They are citations. This is of course a different citationality to a poem, a philosophical reference. This is why there is a 'relative purity' (p. 18) of performatives. However, this is not in opposition to citationality or iterability, but to 'other kinds of iteration within a general iterability', which represents a 'violation' of the 'allegedly rigorous purity of every event of discourse'. Therefore we must not oppose the event to iterability. Rather we must consider the different kinds of iterability and security that apply to our words (a very Austinian task!). The category of intention here does not go away but will not govern 'the entire scene and system of utterance' (p. 18). The intention animating the utterance will never be through and through present to itself and to its content. To recognise the iterability of 
language - to steer clear of the 'lure of consciousness' - prohibits any 'saturation of the context':

By no means do I draw the conclusion that there is no relative specificity of effects of consciousness, or of effects of speech (as opposed to writing in the traditional sense), that there is no performative effect, no effect of ordinary language, no effect of presence or of discursive event (speech act). It is simply that those effects do not exclude what is generally opposed to them, term by term; on the contrary, they presuppose it, in an asymmetrical way, as the general space of their possibility (p. 19).

Therefore, of course, we can say that marrying takes place and can go wrong in the ways identified by Austin, but this does not imply that the fullness he associates with the ways in which words get things done is ever realised. The kinds of failure that Austin refers to come after the initial 'failure' in which words are not subject to an absolute form of contextual control due to the essential iterability internal to them. To see things in this way is to bypass the 'endless alternation of essence and accident' - the idea that things would be 'essentially' so, if it were not for the fact that external contextual factors prohibit this from always being the case. For Austin infelicity is posed as a trap or abyss that language may fall into. This trap surrounds language like a 'ditch' or 'external place of perdition' which can be avoided by remaining 'at home' in the shelter of the 'essence' or 'telos' (p. 17). Derrida notes that Austin does not consider the fact that infelicity should be seen as a law, that a possible risk is a necessary possibility. He does not consider what success might mean once the possibility of infelicity continues to constitute the structure of an utterance.

Of course to talk of infelicity here is to make a value judgement. It means seeing words as in some ways impervious to the control of the speaking subject as something bad. If we agree that any words we use are iterable, then what they do is not entirely under our control. To say 'not entirely' is to account for the relative specificity of effects of consciousness. Nevertheless, there is a decided danger of uncritically adhering to the uniqueness and singularity of linguistic acts - their eventness. The fact that we see things in terms of singularity and uniqueness means that we are trapped in the metaphysical eventness of events and this involves shutting our eyes to the creative possibilities of language. It is therefore necessary to move beyond the stultifying terms of 'success' and 'failure' for these terms only serve to stifle the ordinary ways in which words can take us somewhere else and already are, in some sense, somewhere else - they are not 'ours'. To do this requires us to adopt a simultaneously active and passive approach to language. In the following discussion, we will see what this amounts to in regards to teaching and learning.

\section{Lessons and events}

When considering what Derrida's discussion surrounding iterability, context and events have to do with teaching and learning, we might begin by drawing an analogy between what is currently regarded (in Britain) as 'successful learning' and the notion of infelicity or unhappiness that plays such an important part in Austin's theory of the performative utterance. A successful or happy lesson as it is conventionally understood nowadays must take on board numerous contextual factors (felicity conditions?). So, for example, a good teacher will do the following things (this is not an exhaustive list). 
1. He or she must place the learning objectives/outcomes on the board and make it clear from the beginning of the lesson exactly what it is that is going to be learnt that day.

2. The teacher should ensure that the learning outcomes are differentiated at the outset so that different things are required of different learners with different abilities.

3. Tasks should be differentiated in accordance with both ability/attainment levels and different learning styles, kinaesthetic, auditory and visual.

4. The lesson should incorporate group tasks and individual tasks in which learners work independently.

5. Students should be provided with the tools to assess their work.

6. Behavioural issues should be accounted for through the use of various techniques such as a seating plan that locates students in accordance with their behavioural needs.

7. Activities should be timed in accordance with the anticipation that students may go off-task.

8. Whether or not learning has taken place should be assessed at the end of the lesson through adherence to the learning objectives/outcomes.

The above list represents examples drawn from the set of contextual factors that should be in place for successful (happy?) learning to take place. This notion of success is built into the idea that more old-fashioned pedagogies (if they even deserved the name) failed to account for all sorts of factors necessary for successful communication. Indeed, there are good reasons for thinking that adherence to these contextual factors represents progress in the realm of pedagogy. It seems likely that taking account of different abilities, attributes and behavioural characteristics will prevent the kind of confusion, boredom or chaos that simply ignoring such factors might engender. Equally, there is surely much to recommend the inclusion of different kinds of task, which encourage group or independent learning. What should be noted (and we will return to this) is that most of the things listed above are things we do with words - which is to say things we do with words.

This paper does not aim to debunk the predilections of contemporary pedagogy. However, through adherence to Derrida's reading of Austin, we might see that current approaches to teaching and learning miss something important about context, and how what is missed out is not wholly dissimilar to what is left out of Austin's philosophy when he talks about the total speech act situation. For both Austin and adherents of the contemporary pedagogical norms, context is thought of solely in terms of factors (that are not thought of as linguistic) that need to be in place for successful communication to take place. The didacticism, for example, attributed to traditional forms of teaching is criticised because it is felt that if teachers simply talk to the class or discuss issues with them, then only a certain kind of student (able, auditory, good at concentrating) will benefit. It appears that what is at issue here is the teacher's role as a kind of master - the teacher knows what he or she is talking about and understands the truth of what he or she professes, yet things go wrong (or become unhappy) because simply speaking to the class will not ensure that whatever is in the teacher's head will end up in the students' heads. It should, however, be noted that the contemporary teacher is also expected to be a master, but it is more important that this mastery involves control over contextual factors rather than knowledge (the teacher's knowledge is taken for granted). Consequently, we might note that constative/truth concerns are not at issue here, it is the successful transmission of the constative that is at stake. The assumption here is in keeping with a view of knowledge that sees it as something that floats above us waiting to be communicated in either a successful or unsuccessful way. It is this view of language that had been undermined by Austin in his discussion of the performative aspects of speech. 
We might argue that taking the constative for granted in this way represents a deep suspicion of language. Teachers are often told not to speak too much and when they do speak they should be as clear as possible, otherwise meaning will go awry, their utterances will not be understood. This is surely to acquiesce in securities that are unwarranted. Is there 'always' a danger that students will misunderstand what has been said? If teachers were to come across some examples of post-structuralist writing on education they might be forgiven for thinking that such fears are justified. I am thinking here of the discussion of strong emergence in Osberg and Biesta's 'Beyond presence: epistemological and pedagogical implications of “strong” emergence' (Osberg \& Biesta, 2007, pp. 31-51). Though this article shares some common ground with Osberg and Biesta's, scepticism is closer at hand there than it is here.

The issue that is at stake here concerns whether when teachers speak (particularly when they, heaven forefend, speak 'for a long time'), they are generally misunderstood. To recognise the iterability of language does not lead to scepticism (which would be based on a false metaphysics of the constative) but openness to the flexibility of language and meaning. To speak of flexibility is to take a positive stance on linguistic complexity. If we are constantly afraid that meaning will 'go awry' we will be bound by the kind of value judgement about failure implicit to Austin's argument. It repeats the suspicion of writing and literariness that runs through the tradition of Western philosophy. Yet, As Derrida shows, the very possibility of communication is dependent on the iterability of language, and this iterability requires a necessary division that means words are not at one with themselves. Consequently, trying to pin words down through excessive adherence to clarity is destined to failure, but this is only 'failure' because communication is thought of here as something that must be full and transparent. I am not suggesting that teachers should give up on clarity, but rather that they should be aware of its limitations. Moreover, clarity as such is not simply a contextual quality that can be brought in from outside, or ticked off on a list, it is a quality that pertains to the utterance itself - a facet of a certain way in which we indulge in language.

It is perhaps an over-determined understanding of success and failure that accompanies the more stifling aspects of modern pedagogy. Success is dependent on absolute control of what is being learnt and how it is being learnt. If lessons are to be fully-fledged 'events' then what will be learnt must always be known in advance and necessarily circular (objectives will be returned to at the end of the lesson). It might be argued that to see things otherwise, to embrace the iterability of language will simply lead to chaos. How will we know if anything has been learnt at all? It should be noted here that 'presence' (manifested in the truth of how things are) as an effect of iterability is not something that Derrida seeks to deny or escape from. Rather, seeing presence as an effect of language is to be open to what teaching or 'professing' the truth amounts to. According to Standish:

Derrida explores ways in which the idea of profession requires something tantamount to a pledge, to the freely accepted responsibility to profess the truth. The professor enacts this performative continually in her work: what she says is testimony to the truth; as work it is necessarily an orientation to a to-come. The academic work of professing must then be something more than the (purely constative) statement of how things are. (Standish, 2001, p. 18)

Here Derrida's argument is subtle; professing the truth is about orientating students towards something that neither professor nor student can necessarily predict in which the constative will always be performed as the to-come (an aspect of the future) rather than a statement of that which is secure, of the past, is somehow originary. To take the constative for granted is 
to ignore its performative/iterable aspect. Here we can see that the identification of, and return to, the aims of the lesson and prescribed outcomes, can lead to an impoverished treatment of the areas that are being covered. This partly derives from the constative value that will invariably be ascribed to the outcomes of the lesson; that what will be learnt is known in advance and is in some way foundational. Consequently, the structure of the lesson can drastically inhibit the development of a learning process that has the potential to veer away dramatically from the progression mapped out by that very structure. Here is Standish paraphrasing Derrida:

The responsibility of the professor extends beyond the performatives of criticism to an openness to the event. It must extend beyond the "masterable possible', which is the result of conventions and legitimate fictions, to the surprise of the impossible possible, which has the character of the arrivant. Openness to the impossible possible, something beyond the range of predetermined categories or a purely autonomous control (effective performance), is essential to the exercise and growth of the imagination that this professing requires. (Standish, 2001, p. 18).

It should be noted that for Standish/Derrida the 'event' here is a quite different thing to the kind of 'event' referred to earlier. When Derrida talks about an 'event' in Austin's philosophy he is referring to the 'legitimate fiction' of the 'masterable possible' - the idea that words are under our direct subjective control. Here, 'eventness' can only characterise things in a fully planned sense in which all possibility of failure has been eradicated. Of course such an event can never take place in any full sense. In contrast, this other kind of event attains its 'eventness' from the fact that it is completely unplanned - it arrives. Indeed, the very fact that such an event can take place is dependent on the iterability of language, whereby our words find themselves in unfamiliar territory and 'do' unexpected things.

As Biesta notes in his article 'Witnessing deconstruction in education' (Biesta, 2009, pp. 391404) the idea of the 'arrivant', is central to Derrida's understanding of deconstruction: " "Deconstructions", which I prefer to say in the plural ... is one of the possible names to designate ... what occurs [ce qui n'arrive pas à arriver], namely a radical dislocation, which in effect reiterates regularly - and wherever there is something rather than nothing' (Derrida cited in Biesta, 2009, p. 394). Following Biesta, it is important to note that this treatment of deconstruction radically differs from its treatment in much literature where it has come to denote a ('destructive') form of critique. Deconstruction is not something that one 'does' but something that 'occurs'. Moreover:

...all deconstruction is 'auto-deconstruction' (see Derrida, 1997, p. 9)-deconstruction 'occurs', whether we want it or not. But that doesn't mean that there is nothing to do in relation to deconstruction. While it's not up to us to let deconstruction happen or prevent it from happening, what we can do is to show, to reveal, or, as Bennington (2000, p. 11) has suggested, to witness the occurrence of deconstruction or to be more precise, to witness metaphysics-in-deconstruction. (Biesta, 2009, p. 394)

It is precisely this 'witnessing' of 'metaphysics-in-deconstruction' that Derrida's account of professing alludes to. The metaphysics that undergoes deconstruction is the metaphysics of the constative. Biesta raises the question of why it is important to witness metaphysics in deconstruction. To some degree we have already answered this, in the sense that the metaphysics of the constative presents a false picture of meaning. However, there is clearly more at stake here and this relates to the fact that a particular 'presence' makes other ways of 
seeing invisible. To witness is therefore "to do justice to the "other" of presence'. This shows that 'the point of deconstruction is not negative or destructive but first and foremost affirmative ... It is an affirmation of what is excluded and forgotten; an affirmation of what is other' (p. 395). The emergence of this otherness 'the arrivant' is unforeseeable and 'impossible': 'For Derrida "the impossible" is not what is impossible but what cannot be foreseen as a possibility' (p. 395).

Taking all this into account we can say that 'professing' or teaching with deconstruction in mind is about bearing witness to what is excluded, to what is other. To see things this way is not to simply champion 'openness' as an educational aim but is an attempt to do justice to what has been excluded and show 'hospitality' towards the impossible other that waits at the door. If we ignore this, communication can only be viewed as a 'strictly mechanical, a strictly calculable and predictable process' (Biesta, 2009, p. 399). Moreover, it is 'precisely at the limit of intelligibility that the question of ethics emerges' (Bergdahl, 2009, p. 42).

I should note at this point that the argument presented in this paper departs from Biesta's understanding of 'witnessing' in some important respects. For Biesta, one of the reasons that deconstruction takes place and the arrivant arrives is because communication between sender and receiver must fail due to the fact that the receiver will always 'interpret' what is sent (Biesta, 2009, pp. 396-397). One cannot make a direct comparison between linguistic communication and signals sent from the 'TV studio to another location such as the home' ( $\mathrm{p}$. 396). Though, to a degree, I am in agreement with Biesta on these matters, I wonder if his argument moves toward an overly humanistic or 'personal' vision of Derrida's philosophy and the possibilities that philosophy offers to thinking about education. As we saw in an earlier section of this article 'Signatures', the speaking subject is an effect of presence and undergoes deconstruction. It is therefore not the act of interpretation that issues in the arrivant, but the iterability of language that splits the subject, just as it splits the constative. This is not to say that interpretation is unimportant but rather that it is a secondary complication. Though communication is of course impossible without subjects engaging in discourse, subjectivity itself emerges through language and is an effect of language. Words (and, if you like, their absent traces) come first. It is for this reason that the arrivant can make an appearance when one is performing 'more' solitary tasks such as writing.

The humanistic flavour of Biesta's account also makes itself known in the literal translation of the 'arrivant' as the 'newcomer' which does not just speak of 'new beginnings' but 'new beginners' (p. 400). In contrast, we might think of the arrivant as something darker, more akin to the spectres and ghosts that haunt Derrida's writing. The 'arrivant is also a revenant' (Attridge, 2001, p. 175). This darkness is not an inherent quality that pertains to the arrivant, but is generated by its challenge to the metaphysics of presence, to what 'is'. With this in mind, from the perspective of modern pedagogy, the appearance of the arrivant must generate consternation and unhappiness. Confusion will ensue. How can we assess the class on what has just happened? The mark scheme cannot account for the unexpected. Nevertheless, to wish the event had not occurred will not banish or exorcise it. One can quickly move on to the next fast paced task and pretend that nothing has happened, yet surely the 'happier' (more hospitable?) option is to embrace the arrivant, to face and perhaps affirm our fear of the unexpected. This will not produce anarchy. And I am not proposing some whimsical, unstructured approach to the planning of lessons. The professor should make a stand, but that stand is performative; it opens up and embraces new possibilities. Teachers regularly find that interesting things happen in lessons that affect the structure; that take the lesson into unforeseen territory. Though there can be complete break-ups of structure, for good or ill, this 
is not what I am advocating. Rather, I am thinking of the ways in which a surprise question or unexpected occurrence can alter the structure of the lesson. Aspects that were otherwise hidden will come to the fore in ways that are fruitful. Unfortunately, the current orthodoxy encourages teachers against seeing this as something positive and creative. This orthodoxy is blind to the enhanced potential for learning that the readiness for deconstruction indicated above might provide.

\section{Conclusion}

As mentioned earlier, this paper does not aim to pour scorn on modern teaching methods. Making the aims of the lesson as transparent as possible can certainly help some students to feel more comfortable with what is being learnt yet this is to indulge in language in a particular way (it is not to bring in a manipulative technique from an imaginary extralinguistic zone). By the same token, helping students to come to grips with the assessment process has its benefits, but this too can only benefit from recognition of the subtleties and complexities of language. If the teacher does not take account of the needs of particular students, then a certain amount of unhappiness will ensue. Indeed, if teachers do not try to account for certain factors then their lessons may become chaotic, or deeply confusing. However, the ways in which teachers take account of these factors is often bound up with how they use words. Working with detailed seating plans and consistent routines may have their benefits. However, in my experience, good working relationships with students develop in accordance with a more flexible approach to behavioural issues that involves 'indulging' in 'banter'. To exchange jokes and mild insults with children is, in a sense to be open to the 'event' as Derrida uses the word - surprising things can emerge from this kind of linguistic scenario. Of course, one might argue that 'banter' is simply a distraction from the purposes of the lesson but this surely reflects a very limited conception of what teaching and learning can involve.

Ultimately, the fear of communicative failure clearly has a troubling impact on the ways in which teachers are encouraged to use language. To see the lesson as a singular event in which every possible measure must be taken to ensure transparent communication reflects a paranoia deriving from over-determined considerations regarding success and failure. The fear of failure that haunts the teacher and school is the product of bad metaphysics. As this paper shows, I hope, getting out of this metaphysical trap (through finding a better metaphysics) would help us to live better with our necessary and inevitable 'failures' and the possibilities of teaching and learning they afford. To move beyond paranoia is to reinstate the importance of what the teacher and student have to say. As regards the teacher's words, this is not an appeal to didacticism, but to acknowledge that words require breathing room. The appearance of the arrivant need not be such a painful business.

\section{Notes}

1. The words 'unsatisfactory', 'satisfactory', 'good' and 'outstanding' have simply come to denote a set of characteristics that lessons may or may not conform to. For British inspectors, lessons that are found to be satisfactory now demonstrate an unacceptable set of characteristics. We might also note that from that perspective every teacher could in theory be labelled 'outstanding'. 
2. Though this article deals with universal issues pertaining to language and teaching it also presents a 'localised' critique of pedagogical practice in British schools that will hopefully be of interest to an international audience.

3. The introduction of Derrida as a voice to challenge linguistic scepticism in education might seem strange to some readers. Derrida is often presented as a sceptic through and through who champions the view that you can never be sure what anything means. What this paper hopes to show is that the kind of scepticism that has emerged in education is based on a false metaphysics that Derrida's philosophy helps to counter.

4. To question the extent to which context determines meaning is perhaps particularly apposite in the current educational climate. Reference to context has become a safe philosophical move that appears to display sensitivity and an appropriate depth of understanding. Paying lip service to context has become a mantra, an obstacle to thought. It is important to note that though an analogy will be drawn in this article between Austin's treatment of context and the role context plays in modern pedagogy, the analogy is necessarily loose (see note 11).

5. (A.I) There must exist an accepted conventional procedure having a certain conventional effect, that procedure to include the uttering of certain words by certain persons in certain circumstances, and further,

(A.2) The particular persons and circumstances in a given case must be appropriate for the invocation of the particular procedure invoked.

(B.I) The procedure must be executed by all participants both correctly and

(B.2) completely.

(Г.I) Where, as often, the procedure is designed for use by persons having certain thoughts or feelings, or for the inauguration of certain consequential conduct on the part of any participant, then a person participating in and so invoking the procedure must in fact have those thoughts or feelings, and the participants must intend so to conduct themselves, and further (Г.2) must actually so conduct themselves subsequently (pp. 14-15).

6. Let us return to the statement 'The cat is on the mat'. This looks like as pure an example of a constative statement as one could find. However, as we have already seen, if the cat is under the mat then the statement is unhappy as well as being untrue. On top of this, 'the cat is on the mat' is a favourite phrase that philosophers employ to 'exemplify' a truth claim. Consequently, in exemplifying something, the utterance is 'doing' something.

7. To summarise, Derrida's discussion of the mark demonstrates the unravelling of the binary distinction between speech (as indicative of presence) and writing (as supplement). This distinction depended on the passage from fully present non-linguistic truth passing through into the words of the speaking subject present to that truth. This subject could then turn to the supplementary function of writing. However, if the 'mark' comes first, then, in a sense, writing comes first. Therefore, our understandings of presence, speech and writing have all suffered a sea change-writing can no longer be thought of as simply the secondary representation of speech. Speech is not bound to 'presence', as 'presence' is an effect of the mark. When Derrida talks about 'writing' he is referring to a 'general' writing, which need not be thought of as the word on the page. So, for example, a social group whose culture does 
not involve writing (in the traditional sense) is still subject to writing in the general sense. The fact that the mark may not take a materialised form is, in a sense, immaterial. So, when Levi Strauss maintains that African tribes, because they do not write (in the traditional sense) are in some ways more innocent than Westerners, he fails to recognise the general writing, the 'markness' that characterises their language.

8. This is a literal translation of Derrida's famous formulation 'Il n'y a pas de hors-texte'. As Attridge notes, 'this phrase does not mean 'the things we normally consider to be outside the text do not exist' but 'there is nothing that completely escapes the general properties of textuality, différance etc.' - that is, as Derrida goes on to explain, no 'natural presence' that can be known 'in itself'. But it is also true that here is no inside the text, since this would again imply an inside/outside boundary' (Attridge in Derrida, 1992, p. 102). The more famous (though less exact) translation is 'there is nothing beyond the text'.

9. Polysemy comes into play when a word has two or more similar meanings. Consider the phrases 'the house stood at the foot of the hill' and 'he liked to stand on one foot'.

10. Here 'linguisticism' refers to the tendency to try to define what utterances are and what they do in accordance with semantic or grammatical rules.

11. It should be noted that the 'happiness' referred to here relates to 'effectiveness' and is not meant to allude to positive psychology's treatment of the former.

12. It is important to recognise that several things distinguish Austin from the pedagogues. To begin with, the latter take the constative for granted whereas Austin does not. Also, the 'extra-linguistic' factors that Austin refers to are somewhat different to those that are a feature of modern pedagogy. As mentioned earlier, people do get married. When they fail to do so, this is due to a fairly exceptional set of circumstances. Moreover, the contextual factors Austin alludes to are not annexed to utterances in a forced manner. The manipulation of context that characterises fashionable teaching methods is of a rather different order to the treatment of context in Austin's work. We do not wilfully construct authenticity. That said, Austin's philosophy still presents an overly simplistic and over-determined treatment of context.

13. As we shall see this account of professing is radically at odds with what tends to count as 'professionalism' today.

14. Biesta's reading of 'Signature, Event Context' is similar to my own. However, one significant difference is that Biesta associates Derrida's account of communicative failure with complications surrounding the receiver's interpretation of the message (Biesta, 2009, p. 399)

15. Biesta does not explicitly mention the arrivant here, but I take it as read that this is what he is referring to.

16. My experience of working as an examiner represented a particularly severe induction into the religion of the constative, for, as Biesta notes, assessment is 'the mechanism that constantly tries to close the gap between teaching and learning. It does this by saying "this is right" and "this is wrong"- and, more often, by saying "you are right" and "you are wrong". In a sense it is as simple as that. But because the slippage is there all the time, achieving closure in education require 


\section{References}

Attridge, D. 2001. "Ghost writing". In Deconstruction: a reader, Edited by: McQuillan, M. 175-178. New York: Routledge

Austin, J.L. 1976. How to do things with words, London: Oxford University Press

Bergdahl, L. 2009. Lost in translation: on the untranslatable and its ethical implications for religious pluralism. Journal of Philosophy of Education, 43(1): 31-44.

Biesta, J.J. 2009. Witnessing deconstruction in education: why quasi-transcendentalism matters. Journal of Philosophy of Education, 43(3): 391-404.

Cavell, S. 2005. Philosophy the day after tomorrow, Cambridge, MA: Harvard University Press

Derrida, J. 1988. "Signature event context”. In Limited Inc., Edited by: Graff, G., Weber, S. and Mehlman, J. Evanston: Northwestern University Press

Derrida, J. 1992. Acts of literature, Edited by: Attridge, D. New York \& London: Routledge

Osberg, D. and Biesta, J.J. 2007.Beyond presence: epistemological and pedagogical implications of 'strong' emergence. Interchange, 38(1): 31-51.

Standish, P. 2001. Disciplining the profession: subjects subject to procedure. Education, Philosophy and Theory, 34(1): 5-23. 